\title{
Public Good Provision: Lindahl Tax, Income Tax, Commodity Tax, and Poll Tax, A Simulation
}

\author{
$\underline{\text { T. Fukiharu }}$ \\ School of Social Informatics, Aoyama Gakuin University \\ Email:fukiharu@si.aoyama.ac.jp
}

\begin{abstract}
There are two traditions in the argument on taxation. On the one hand, the argument on taxation is constructed in such a way that which taxation is desirable in order to impose a tax, income tax, commodity tax or poll tax, without paying any attention on why the tax is necessary. In the partial equilibrium framework, the lump-sum tax, such as poll tax, is regarded as the best. On the other hand, it is also a tradition to assert that government imposes a tax in order to provide public goods. This paper integrates the above two traditions by constructing a primitive general equilibrium (GE) model which incorporates a public good, asking which taxation is desirable in order to impose tax, income tax, commodity tax, or poll tax to optimally provide the public good. Formally, in Part I, we start with utilizing the Lindahl mechanism to compute a Pareto-optimal public good level under a specification of the parameters on production and utility functions. The burden-sharing in this Lindahl mechanism may be regarded as a tax on the society members, while utilizing pseudo-market mechanism. We call it Lindahl tax. Next, we compute the rate of income tax in order to sustain the optimal public good level, and compare the Lindahl tax and income tax. We proceed to the computation of the rate of (proportional) commodity tax in order to sustain the optimal public good level, and compare the Lindahl tax, income tax and commodity tax. Finally we proceed to the comparison between the Lindahl tax, income tax, commodity tax and poll tax under the specification of the model. In Part II, selecting the parameters randomly, we examine the robustness of the conclusion in Part I. Production functions are assumed as the Cobb-Douglass type while the utility function as the CES type with $k$ the substitution parameter. It was shown for a specified case that when $0<k<1$, there exists no general equilibrium for the poll tax case, while the income tax (and proportional commodity tax) is more desirable than the Lindahl tax not only from the fairness viewpoint but also from the utilitarian efficiency viewpoint under some specification of parameters. It was also shown for another specified case that even when $0<k<1$, there exists general equilibrium for the poll tax case, and the income tax and the commodity tax is more desirable than the Lindahl tax, while the comparison between the poll taxation and other taxations are impossible from the above mentioned two viewpoints. Finally, specifying parameters on production and utility functions and initial endowments randomly, this paper showed that when $0<k<1$, the income tax (and proportional commodity tax) is more desirable than the Lindahl tax from the fairness and efficiency viewpoints with high possibility of non-existence for poll tax general equilibrium. However, when $k<0$, specifying parameters on production and utility functions and initial endowments randomly, this paper showed that the Lindahl tax is more desirable than the income tax (and proportional commodity tax) from the fairness and efficiency viewpoints with high possibility of existence for poll tax although the comparison between the poll tax and other taxes are impossible from the two viewpoints. Thus, this paper showed that the comparison completely depends on the substitution parameter of the CES utility function.
\end{abstract}

Keywords: General equilibrium, public good, Lindahl mechanism, income tax, commodity tax, poll tax 


\section{INTRODUCTION}

There are two traditions in the argument on taxation. On the one hand, the argument on taxation is constructed in such a way that which taxation is desirable in order to impose a tax, income tax, commodity tax or poll tax, without paying any attention on why the tax is necessary. In the partial equilibrium framework, Stiglitz [2000, Chapter 17] regards the lump-sum tax, such as poll tax, the best. On the other hand, it is also a tradition to assert that government imposes a tax in order to provide public goods (Stiglitz [2000, Chapter 4]). This paper combines the above two traditions by constructing a primitive general equilibrium (GE) model which incorporates a public good, asking which taxation is desirable in order to impose tax, income tax, commodity tax, or poll tax to provide the public good.

Formally, in Part I, first, we utilize the Lindahl mechanism to compute a Pareto-optimal public good level under a specification of the parameters. The burden-sharing in this Lindahl mechanism may be regarded as a tax on the society members, while utilizing pseudo-market mechanism. We call it Lindahl tax. Next, we compute the rate of income tax in order to sustain the optimal public good level, and compare the Lindahl tax and income tax. We proceed to the computation of the rate of (proportional) commodity tax in order to sustain the optimal public good level, and compare the Lindahl tax, income tax and commodity tax. Finally we proceed to the comparison between the Lindahl tax, income tax, commodity tax and poll tax under the specification of the model. In Part II, selecting the parameters randomly, we examine the robustness of the conclusion in Part I.

\section{ECONOMY WITH PUBLIC GOOD AND WALRAS - LINDAHL MECHANISM: SPECIFIED GE MODEL}

We start with constructing a primitive GE model which incorporates a public good. The production and utility functions are specified by particular functions, and their parameters are also specified. Utilizing Walras-Lindahl mechanism, the optimal level of public good, as well as burden-sharing of each member of the society, is derived.

\subsection{Assumptions on Production Side}

Country $A$ is under national isolation. She has three sectors of production, which produces 3 goods, utilizing labor, $L_{i}$, and capital, $K_{i}: y$ stands for the output of sector 1, $x$ stands for the output of sector 2, and $z$ stands for the output of sector $3(i=1,2,3)$, where $y$ and $x$ are private goods and $z$ is a public good. Production function of sector $1, y=f_{1}=L_{1}{ }^{a 1} K_{1}{ }^{b 1}$, with $a_{1}+b_{1}<1$ : decreasing returns to scale, is specified by $f_{1}=L_{1}{ }^{1 / 6} K_{1}{ }^{1 / 5}$. Production function of sector $2, x=f_{2}=L_{2}{ }^{a 2} K_{2}{ }^{b 2}$, with $a_{2}+b_{2}<1$ : decreasing returns to scale, is specified by $f_{2}=L_{2}{ }^{1 / 4} K_{2}{ }^{1 / 3}$. Production function of sector $3, z=f_{3}=L_{3}{ }^{a 3} K_{3}{ }^{b 3}$, with $a_{3}+b_{3}=1$ : constant returns to scale, is specified by $f_{3}=L_{3}{ }^{1 / 3} K_{3}{ }^{2 / 3}$. From the profit maximization of the sector 1, demand for labor, $L_{1}{ }^{\mathrm{D}}$, and demand for capital, $K_{1}^{\mathrm{D}}$, are computed with $p_{y}$, the price of the consumption good, $y, w_{L}$, the wage rate of labor, and $w_{K}$, the rental price of capital, as parameters. Thus, the supply function of $y, y^{S}$, is computed with $p_{y}$, $w_{L}$, and $w_{K}$, as parameters. The profit function of sector $1, \pi_{1}$, is computed, with $p_{y}, w_{L}$, and $w_{K}$, as parameters. This profit accrues to entrepreneur 1. From the profit maximization of the sector 2, demand for labor, $L_{2}{ }^{\mathrm{D}}$, and demand for capital, $K_{2}{ }^{\mathrm{D}}$, are computed with $p_{x}$, the price of the consumption good, $x, w_{L}$ and $w_{K}$ as parameters. Thus, the supply function of $x, x^{S}$, is computed with $p_{x}, w_{L}$, and $w_{K}$, as parameters. The profit function of sector $2, \pi_{2}$, is computed, with $p_{x}, w_{L}$, and $w_{K}$, as parameters. This profit accrues to entrepreneur 2. The sector 3 produces a public good, $z$, under constant returns to scale, so that demand for capital, $K_{3}{ }^{\mathrm{D}}$, and the one for labor, $L_{3}{ }^{\mathrm{D}}$, is derived by the minimizing cost, given output level $z$, with $w_{L}$ and $w_{K}$, as parameters. The price of the public good, $p_{z}$, is determined so that $p_{z} z=w_{L} L_{3}{ }^{\mathrm{D}}+w_{K} K_{3}{ }^{\mathrm{D}}$.

\subsection{Assumptions on Consumption Side}

We proceed to the demand side of country A. She is endowed with the initial labor, $L_{e}$, and the initial capital, $K_{e}$. In this paper, the aggregate worker possesses $\alpha_{\mathrm{L}}$ of $L_{e}$ and $\beta_{\mathrm{L}}$ of $K_{e}$, while the aggregate capitalist possesses $\alpha_{\mathrm{K}}$ of $L_{e}$ and $\beta_{\mathrm{K}}$ of $K_{e}$, where $\alpha_{\mathrm{L}}+\alpha_{\mathrm{K}}=1$ and $\beta_{\mathrm{L}}+\beta_{\mathrm{K}}=1$. It is specified in this section that $L_{e}=100$, $K_{e}=50, \alpha_{\mathrm{L}}=1, \alpha_{\mathrm{K}}=0, \beta_{\mathrm{L}}=0$, and $\beta_{\mathrm{K}}=1$. All the agents in this paper: (aggregate) workers, (aggregate) capitalists, and 2 entrepreneurs, have the same CES utility function, $u[y, x, z]=\left(\gamma_{y} y^{k}+\gamma_{x} x^{k}+\gamma_{z} z^{k}\right)^{1 / k}$ which is specified as $u[y, x, z]=\left(y^{1 / 2}+x^{1 / 2}+z^{1 / 2}\right)^{2}$ : i.e. $k=1 / 2, \gamma_{y}=\gamma_{x}=\gamma_{z}=1$. All the consumers maximize utility subject to income constraint:

$$
\max u[y, x, z] \text { s.t. } p_{y} y+p_{x} x+\theta_{j} p_{z} z=m_{j}(j=L, K, 1,2)
$$

where $m_{j}$ is income and $\theta_{j}$ is the burden share of the household $j$ for the public good $(j=L, K, 1,2,3)$. The 
Fukiharu, Public Good Provision: Lindahl Tax, Income Tax, Commodity Tax, and Poll Tax, A Simulation

aggregate workers (household $L$ )'s income, $m_{L}$, consists of initial endowment of labor, evaluated by the wage rate: $w_{L} L_{e}$. It is assumed that they supply $L_{e}$ for labor supply. The aggregate capitalists (household $K$ )'s income, $m_{K}$, consists of initial endowment of capital, evaluated by the rental price of capital: $w_{K} K_{e}$. It is assumed that they supply $K_{e}$ for capital supply. Entrepreneur 1 (household 1)'s income, $m_{1}$, consists of profit for the sector 1, $\pi_{1}$. Finally, entrepreneur 2 (household 2)'s income, $m_{2}$, consists of profit for the sector $2, \pi_{2}$.

From (1) the demand function of workers for commodity $y, y_{L}^{\mathrm{D}}$, that for commodity $x, x_{L}^{\mathrm{D}}$, that for commodity $z, z_{L}^{\mathrm{D}}$, the demand function of capitalists for commodity $y, y_{K}^{\mathrm{D}}$, that for commodity $x, x_{K}^{\mathrm{D}}$, that for commodity $z, z_{K}^{\mathrm{D}}$, the demand function of entrepreneur 1 for commodity $y, y_{E 1}{ }^{\mathrm{D}}$, that for commodity $x$, $x_{E 1} \mathrm{D}$, that for commodity $z, z_{E 1} \mathrm{D}$, and finally the demand function of entrepreneur 2 for commodity $y, y_{E 2} \mathrm{D}$, that for commodity $x, x_{E 2}$, that for commodity $z, z_{E 2}{ }^{\mathrm{D}}$ are derived.

\subsection{General Equilibrium with Public Good: Walras-Lindahl Equilibrium with Lindahl Tax}

General equilibrium for country A with public good, "GE with public good”, or Walras-Lindahl equilibrium, is defined by the following system of simultaneous equations.

$$
\begin{aligned}
& y_{L}{ }^{\mathrm{D}}+y_{K}{ }^{\mathrm{D}}+y_{E 1}{ }^{\mathrm{D}}+y_{E 2}{ }^{\mathrm{D}}=y^{\mathrm{S}} \\
& x_{L}{ }^{\mathrm{D}}+x_{K}{ }^{\mathrm{D}}+x_{E 1}{ }^{\mathrm{D}}+x_{E 2}{ }^{\mathrm{D}}=x^{\mathrm{S}} \\
& z_{L}{ }^{\mathrm{D}}=z_{K}{ }^{\mathrm{D}}=z_{E 1}{ }^{\mathrm{D}}=z_{E 2}{ }^{\mathrm{D}}=z \\
& L_{1}{ }^{\mathrm{D}}+L_{2}{ }^{\mathrm{D}}+L_{3}{ }^{\mathrm{D}}=L_{e} \\
& K_{1}{ }^{\mathrm{D}}+K_{2}{ }^{\mathrm{D}}+K_{3}{ }^{\mathrm{D}}=K_{e}
\end{aligned}
$$

From the application of Newton method on (2), (3), (4) and (6) we compute the GE with public good as in what follows with $w_{L}=1$.

$$
\begin{aligned}
& p_{x}=14.153545624140019458, p_{y}=19.279639252690992305, \\
& w_{K}=3.8103703458622201692, \theta_{1}=0.061932787239262383167, \\
& \theta_{L}=0.32500153599364843437, \theta_{K}=0.55737371673138213739, \\
& \mathrm{z}=56.385555537178640578, p_{z}=4.6104790191979988818
\end{aligned}
$$

It is confirmed that (7) satisfies (5). This "GE with public good" is also derived by the following WalrasLindahl differential equations, in which $t$ stands for time.

$$
\begin{aligned}
& \mathrm{d} p_{y}[t] / \mathrm{d} t=y_{L}{ }^{\mathrm{D}}+y_{K}^{\mathrm{D}}+y_{E 1}{ }^{\mathrm{D}}+y_{E 2} \mathrm{D}-y^{\mathrm{S}} \\
& \mathrm{d} p_{x}[t] / \mathrm{d} t=x_{L}^{\mathrm{D}}+x_{K}^{\mathrm{D}}+x_{E 1} \mathrm{D}+x_{E 2} \mathrm{D}-x^{\mathrm{S}} \\
& \mathrm{d} w_{K}[t] / \mathrm{d} t=K_{1}^{\mathrm{D}}+K_{2}^{\mathrm{D}}+K_{3}^{\mathrm{D}}-K_{e} \\
& \mathrm{~d} \theta_{L}[t] / \mathrm{d} t=z_{L}^{\mathrm{D}}-\left(z_{L}^{\mathrm{D}}+z_{K}^{\mathrm{D}}+z_{E 1} \mathrm{D}+z_{E 2}{ }^{\mathrm{D}}\right) / 4 \\
& \mathrm{~d} \theta_{K}[t] / \mathrm{d} t=z_{K}^{\mathrm{D}}-\left(z_{L}^{\mathrm{D}}+z_{K}^{\mathrm{D}}+z_{E 1} \mathrm{D}+z_{E 2} \mathrm{D}\right) / 4 \\
& \mathrm{~d} \theta_{1}[t] / \mathrm{d} t=z_{E 1} \mathrm{D}-\left(z_{L}^{\mathrm{D}}+z_{K}^{\mathrm{D}}+z_{E 1} \mathrm{D}+z_{E 2}{ }^{\mathrm{D}}\right) / 4 \\
& \mathrm{~d} z[t] / \mathrm{d} t=z_{E 2} \mathrm{D}-z[t]
\end{aligned}
$$

The set of GE incomes after the deduction of Lindahl tax (payment for the consumption of public good), $\left\{m_{L}^{*}, m_{K}^{*}, m_{E 1}{ }^{*}, m_{E 2}{ }^{*}\right\}$, and the one of GE utility levels, $\left\{u_{L}^{*}, u_{K}^{*}, u_{E 1}^{*}, u_{E 2}{ }^{*}\right\}$ are given respectively as in what follows.

$\{15.51116393955550368,45.62118185947570415,0.56326765368126488,0.45546873059374796\}$

$\{78.98947171601549650,97.48133120570986636,60.39985087702961566,59.9890859141016334\}$

The Gini coefficients before and after the Lindahl tax, $G i n i^{L 0}$ and $G i n i^{L}$, are given respectively as in what follows.

$$
\operatorname{Gini}^{L O}=0.4735038882324976043, \text { Gini }^{L}=0.605158552303251932
$$

\subsection{General Equilibrium with Public Good: Income Tax Provision of Public Good}

In this subsection, we examine if it is possible to use income tax instead to Lindahl tax in order to achieve the optimum public good level, $z^{O}=56.385555537178640578$. Since $z^{O}$ is provided for each member of the society, the utility function becomes the following one $u\left[y, x, z^{O}\right]$.

All the consumers maximize utility subject to income constraint: 
Fukiharu, Public Good Provision: Lindahl Tax, Income Tax, Commodity Tax, and Poll Tax, A Simulation

$$
\max u\left[y, x, z^{O}\right] \text { s.t. } p_{y} y+p_{x} x=\left(1-\tau_{I}\right) m_{j} \quad(j=L, K, 1,2)
$$

One of the GE conditions, (4), is replaced by the following.

$$
p_{z} z=\tau_{I}\left(w_{L} L_{e}+w_{K} K_{e}+\pi_{1}+\pi_{2}\right)
$$

Utilizing the Newton method, we obtain the following GE prices and tax rate.

$$
\begin{aligned}
& p_{x}=14.153545624140019458, p_{y}=19.279639252690992305, \\
& w_{K}=3.8103703458622201692, p_{z}=4.6104790191979988818, \\
& \tau_{I}=0.80705342770025117950
\end{aligned}
$$

From (7) and (12) it is clear that we exactly the same GE prices. The set of GE incomes after the deduction of income tax $\left\{m_{L}^{* I}, m_{K}^{* I}, m_{E 1}{ }^{* I}, m_{E 2}{ }^{* I}\right\}$, and the one of GE utility levels, $\left\{u_{L}{ }^{* I}, u_{K}{ }^{* I}, u_{E 1}{ }^{* I}, u_{E 2}{ }^{* I}\right\}$ are given respectively as in what follows.

$\{19.294657229974882050,36.75989487133618914,3.215182344307003283,2.881347737688146198\}$ $\{81.84038782010972444,92.76133922986662403,66.20540091536471678,65.66174123232441454\}$

From the viewpoint of Bentham-type utilitarian, the income tax is more desirable than the Lindahl tax, since the sum of utility for the former case is greater than the one for the latter case, as shown in what follows.

$$
u_{L}{ }^{I}+u_{K} *^{I}+u_{E 1} * I+u_{E 2} * I=306.4688691976654798>296.8597397128566119=u_{L}^{*}+u_{K}^{*}+u_{E 1} *+u_{E 2} *
$$

Furthermore, the income tax is more desirable than the Lindahl tax in the sense that the Gini coefficient for the former, Gini ${ }^{I}$ is smaller than the latter case, as shown in what follows.

$$
\text { Gini }^{I}=0.4735038882324976043
$$

From (9) and (13) it is clear that the Gini coefficient for income tax is exactly the same as the pre-tax Gini coefficient for Lindahl tax case.

\subsection{General Equilibrium with Public Good: Proportional Commodity Tax Provision of Public Good}

In this subsection, we examine if it is possible to use proportional commodity tax instead to Lindahl tax in order to achieve the optimum public good level, $z^{O}$.

All the consumers maximize utility subject to income constraint:

$$
\max u\left[y, x, z^{O}\right] \text { s.t. }\left(1-\tau_{C}\right) p_{y} y+\left(1-\tau_{C}\right) p_{x} x=m_{j} \quad(j=L, K, 1,2)
$$

One of the GE conditions, (4), is replaced by the following.

$$
p_{z} z=\tau_{C} p_{y}\left(y_{L}^{\mathrm{D}}+y_{K}{ }^{\mathrm{D}}+y_{E 1}{ }^{\mathrm{D}}+y_{E 2}{ }^{\mathrm{D}}\right)+\tau_{C} p_{x}\left(x_{L}^{\mathrm{D}}+x_{K}^{\mathrm{D}}+x_{E 1}{ }^{\mathrm{D}}+x_{E 2}{ }^{\mathrm{D}}\right)
$$

It is confirmed that exactly the same GE prices utilities and incomes are derived as in the income tax case except for the proportional commodity tax rate, $\tau_{C}=4.18278$. Thus, the proportional commodity tax is more desirable than the Lindahl tax.

\subsection{General Equilibrium with Public Good: Poll Tax Provision of Public Good}

In this subsection, we examine if it is possible to use poll tax instead to Lindahl tax in order to achieve the optimum public good level, $z^{O}$.

All the consumers maximize utility subject to income constraint:

$$
\max u\left[y, x, z^{O}\right] \text { s.t. } p_{y} y+p_{x} x=\left(m_{j}-T / 4\right) \quad(j=L, K, 1,2)
$$

where $m_{j}$ is pre-tax income and $T$ is the tax to sustain $z^{O}(j=L, K, 1,2)$. One of the GE conditions, (4), is replaced by the following. 
Fukiharu, Public Good Provision: Lindahl Tax, Income Tax, Commodity Tax, and Poll Tax, A Simulation

$$
p_{z} z=T
$$

It is confirmed that exactly the same GE prices and utilities are derived as in the income tax case except for the poll tax, $T=259.96442078998567379$. It must be noted, however, that the poll tax cannot sustain $z^{O}$, since the income after the poll tax is negative for entrepreneurs 1 and 2.

$$
\pi_{1}-T / 4=-48.327516381250892247, \pi_{2}-T / 4=-50.05770833356105865
$$

(The computation in Section 2 was conducted in Fukiharu [2012a] .)

\section{ROBUSTNESS OF THE SPECIFIED GE MODEL}

In this section, we examine the robustness of the conclusion in Section 2. First, modification of parameters is made, in order to examine the conclusion. Suppose that $a_{1}=2 / 3, b_{1}=1 / 8, a_{2}=1 / 2, b_{2}=1 / 3, a_{2}=3 / 5, b_{3}=2 / 5$, $L_{e}=100, K_{e}=50, \alpha_{\mathrm{L}}=2 / 3, \alpha_{\mathrm{K}}=1 / 5, \beta_{\mathrm{L}}=1 / 3$, and $\beta_{\mathrm{K}}=4 / 5, k=1 / 2, \gamma_{y}=\gamma_{x}=1$, and $\gamma_{z}=1 / 100$.

\subsection{General Equilibrium with Public Good: Walras-Lindahl Equilibrium with Lindahl Tax}

The Gini coefficients before and after the Lindahl tax and the Bentham-type utilitarian social utility level are given respectively as in what follows.

$$
\begin{aligned}
& G_{i n i}{ }^{L 0}=0.3309739379674684046, \text { Gini }^{L}=0.3310327896068688795 \\
& u_{L}{ }^{*}+u_{K} *+u_{E 1} *+u_{E 2} *=84.53727799264331946
\end{aligned}
$$

\subsection{General Equilibrium with Public Good: Income Tax Provision of Public Good}

The Gini coefficients and the Bentham-type utilitarian social utility level are given respectively as in what follows.

$$
\begin{aligned}
& G i n i^{I}=0.3309739379674684046=\text { Gini }^{L 0}<\text { Gini }^{L} \\
& u_{L}{ }^{* I}+u_{K}{ }^{* I}+u_{E 1}{ }^{* I}+u_{E 2}{ }^{* I}=84.53727972251664468>u_{L} *+u_{K} *+u_{E 1} *+u_{E 2} *
\end{aligned}
$$

Thus, we have the same conclusion as in Section 2: the income tax is more desirable than the Lindahl tax.

\subsection{General Equilibrium with Public Good: Proportional Commodity Tax Provision of Public Good}

We have exactly the same conclusion as in section 2: the proportional commodity tax produces exactly the same GE prices and quantities.

\subsection{General Equilibrium with Public Good: Poll Tax Provision of Public Good}

In comparison with section 2 , the optimum public good level, $z^{O}=0.038835026401740385141$ is so small, and the poll tax, $T=0.069480915195488934423$ is also so small, that $z^{O}$ can be supported by $T$. Every member has positive income after paying the poll tax. The Gini coefficient, $\operatorname{Gini}^{P}$, and the Bentham-type utilitarian social utility level, $u_{L}{ }^{P}+u_{K}{ }^{* P}+u_{E 1}{ }^{P}+u_{E 2} *^{P}$, are given respectively as in what follows.

$$
\begin{aligned}
& \text { Gini }^{P}=0.3311077313088771057>\text { Gini }^{L}>\text { Gini }^{I} \\
& u_{L}{ }^{P}+u_{K}{ }^{P}+u_{E 1}{ }^{P}+u_{E 2}{ }^{P}=84.53727576387538624<u_{L}^{*}+u_{K} *+u_{E 1} *+u_{E 2} *<u_{L}{ }^{I}+u_{K}{ }^{I}+u_{E 1} *^{I}+u_{E 2}{ }^{* I}
\end{aligned}
$$

Thus, the income tax is the best taxation and the poll tax is the worst taxation. (The computation in Section 3 was conducted in Fukiharu [2012b].)

\section{SIMULATIONS}

The analysis in Section 2 and 3 might suggest that the income tax and the proportional commodity tax are the most desirable taxation. It must be noted, however, that $k=1 / 2$ is assumed. If $k$ is selected differently it is not clear that the above conclusion is robust. Therefore simulations are necessary with $k$ selected different from $1 / 2$.

\subsection{Simulation when $0<k<1$}

In this subsection, we conduct a simulation to compare the desirability of taxes to provide the public good by 
selecting parameters randomly when $0<k<1$.

In what follows, first, 100 tuples of parameters for $\left\{a_{1}, b_{1}, a_{2}, b_{2}, a_{3}, b_{3}, L_{e}, K_{e}, \alpha_{L}, \alpha_{K}, \beta_{L}, \beta_{K}, k, \gamma_{y}, \gamma_{x}, \gamma_{z}\right\}$ are selected randomly, where $a_{i}+b_{i}<1, i=1,2, a_{3}+b_{3}=1, \alpha_{L}+\alpha_{K}=1, \beta_{L}+\beta_{K}=1$, and $0<k<1$ are satisfied and $a_{i}$, $b_{j}$ and $\alpha_{L}$ etc. and $k$ are expressed by $n / m$ for integers $n$ and $m$ which belongs to [1,10], $L_{e}$ and $K_{e}$ are integers belonging to $[1,1000]$, and $\gamma_{y}, \gamma_{x}, \gamma_{z}$ are integers belonging to $[1,10]$. Next, we apply them to the Mathematica program to compute GE prices, tax rates, utilities, and incomes. Among 100 simulations only 65 simulations satisfy required 22 equilibrium conditions. The reason for the smallness of the number stems from the Newton method itself, on which stability of the process crucially depends on the initial position. In order to raise the number, we must search for the initial position which guarantees the stability of the process for each simulation. Unfortunately, however, in this paper fixed initial position is utilized. Among 65 "successful" simulations, 59 cases satisfied Gini ${ }^{L}>\operatorname{Gini}^{I}$ and $u_{L} *+u_{K} *+u_{E 1} *+u_{E 2} *<u_{L}{ }^{I}+u_{K}{ }^{* I}+u_{E 1}{ }^{* I}+u_{E 2}{ }^{* I}$. In other words, $90 \%$ of the "successful" simulations guaranteed the conclusion in Section 2. Among the "unsuccessful" simulations, there existed some complex-number-income solutions for the poll tax, so that the comparison between the poll taxation and other taxations was not done.

We repeated this simulations 50 times. The following data shows the shares of the cases which satisfied Gini ${ }^{L}>$ Gini $^{I}$ and $u_{L}{ }^{*}+u_{K} *+u_{E 1} *+u_{E 2} *<u_{L}{ }^{I}+u_{K}{ }^{I}+u_{E 1}{ }^{*}+u_{E 2}{ }^{* I}$ among the "successful" simulations.

$\{0.913793,0.934426,0.939394,0.896552,0.936508,0.955882,0.921875,0.875,0.924528,0.923077$, $0.983871,0.898551,0.903226,0.964286,1,0.95082,0.870968,0.940299,0.919355,0.931034,0.963636$, $0.919355,0.916667,0.962963,0.916667,0.890909,0.980769,0.935484,0.984848,0.958904,0.916667,0.9$, $0.876923,0.983333,0.965517,0.916667,0.955224,0.9375,0.9375,0.861538,0.984375,0.82,0.936508$, $0.885714,0.915254,0.901639,0.857143,0.936508,0.935484,0.919355\}$

Thus we may conclude that more than $90 \%$ of the "successful" simulations guaranteed the conclusion in Section 2.

\subsection{Simulation when $-10<k<0$}

In this subsection, we conduct a simulation to compare the desirability of taxes to provide the public goods by selecting parameters randomly when $k<0$. It was ascertained first that when $k=-2\left(a_{1}=1 / 8, b_{1}=4 / 5, a_{2}=5 / 6\right.$, $b_{2}=1 / 7, a_{2}=2 / 7, b_{3}=5 / 7, L_{e}=348, K_{e}=878, \alpha_{\mathrm{L}}=1 / 2, \alpha_{\mathrm{K}}=1 / 2, \beta_{\mathrm{L}}=4 / 9$, and $\beta_{\mathrm{K}}=5 / 9, k=-2, \gamma_{v}=13, \gamma_{x}=9$, and $\left.\gamma_{z}=4\right)$, we have $\operatorname{Gini}^{L}<\operatorname{Gini}^{I}$ and $u_{L}{ }^{*}+u_{K} *+u_{E 1} *+u_{E 2}{ }^{*}>u_{L}{ }^{I}+u_{K}{ }^{* I}+u_{E 1}{ }^{I}+u_{E 2}{ }^{I I}$, with 22 equilibrium conditions satisfied. Thus, in this specified case, Lindahl tax is more desirable than income tax and commodity tax. This conclusion is completely opposite to Fukiharu [2012b]. In this case, the poll tax is feasible, but the comparison between the poll tax and other taxes was impossible. Note that $k<0$ does not violate the decreasing marginal rate of substitution.

In what follows, first, 100 tuples of parameters for $\left\{a_{1}, b_{1}, a_{2}, b_{2}, a_{3}, b_{3}, L_{e}, K_{e}, \alpha_{L}, \alpha_{K}, \beta_{L}, \beta_{K}, k, \gamma_{y}, \gamma_{x}, \gamma_{z}\right\}$ are selected randomly, where $a_{i}+b_{i}<1, i=1,2, a_{3}+b_{3}=1, \alpha_{L}+\alpha_{K}=1, \beta_{L}+\beta_{K}=1$, and integer $k$ with $-10<k<0$ are satisfied and $a_{i}, b_{i}$ and $\alpha_{L}$ etc. are expressed by $n / m$ for integers $n$ and $m$ which belongs to $[1,10], L_{e}$ and $K_{e}$ are integers belonging to [1,1000], and $\gamma_{y}, \gamma_{x}, \gamma_{z}$ are integers belonging to [1,10]. Among 100 simulations only 33 cases satisfied 22 equilibrium conditions. The reason for the smallness of the number stems from the Newton method itself, as explained in the previous subsection. We repeated this 100 -simulation session 50 times. The following data shows the number of simulations in each session which satisfy 22 equilibrium conditions.

$\{28,37,34,35,32,29,26,26,27,34,28,34,30,26,28,25,32,33,27,31,25,29,27,36,28,32,23,32,25$, $37,33,33,28,21,29,25,23,30,31,33,34,25,32,33,34,31,30,32,28,32\}$

Even though the probability of "successful" Newton method convergence is approximately $30 \%$, among the "successful" simulations the probability of the occurrence of Gini ${ }^{L}<\operatorname{Gini} i^{I}$ and $u_{L}{ }^{*}+u_{K}{ }^{*}+u_{E 1}{ }^{*}+u_{E 2}{ }^{*}>u_{L}{ }^{*} I_{+}$ $u_{K}{ }^{I}+u_{E 1}{ }^{I}+u_{E 2}{ }^{*}$ is quite high.

For the above-mentioned repeated 50 sessions, the following data shows the shares of the cases whose conclusion is completely opposite to Fukiharu [2012b] among the "successful" simulations with 22 equilibrium conditions satisfied.

$\{0.928571,0.972973,0.970588,1,0.9375,0.931034,1,1,1,0.970588,1,1,1,0.961538,0.964286,0.96,1$, $0.969697,1,1,1,1,0.962963,0.944444,0.964286,0.96875,0.913043,0.9375,1,0.945946,1,1,0.964286$, $1,1,0.92,1,0.966667,0.967742,1,0.970588,1,1,1,0.970588,1,0.966667,0.96875,0.928571,0.96875\}$ 
Fukiharu, Public Good Provision: Lindahl Tax, Income Tax, Commodity Tax, and Poll Tax, A Simulation

Thus, more than $95 \%$ is the probability of the occurrence of $\operatorname{Gini}^{L}<G i n i^{I}$ and $u_{L} *+u_{K}^{*+}+u_{E 1} *+u_{E 2} *>u_{L}{ }^{I}+$ $u_{K}{ }^{I}+u_{E 1}{ }^{I}+u_{E 2}{ }^{I}$. (The computation in Section 3 was conducted in Fukiharu [2013].)

\section{CONCLUSIONS}

The aim of this paper was to integrate the two traditions of public economics. By constructing a primitive general equilibrium model which incorporates a public good, this paper asks which taxation is desirable in order to impose tax, say, Lindahl taxation, income taxation, commodity taxation, or poll taxation, to provide the public good. Production functions are assumed as the Cobb-Douglass type while the utility function as the CES type with $k$ the substitution parameter. It was shown for a specified case that when $0<k<1$, there exists no general equilibrium for the poll tax case, while the income tax (and proportional commodity tax) is more desirable than the Lindahl tax not only from the fairness viewpoint but also from the utilitarian efficiency viewpoint under some specification of parameters. It was also shown for another specified case that even when $0<k<1$, there exists general equilibrium for the poll tax case, and the income tax and the commodity tax is more desirable than the Lindahl tax, while the comparison between the poll taxation and other taxations are impossible from the above mentioned two viewpoints.

Finally, specifying parameters on production and utility functions and initial endowments randomly, this paper showed that when $0<k<1$, the income tax (and proportional commodity tax) is more desirable than the Lindahl tax from the fairness and efficiency viewpoints with high possibility of non-existence for poll tax general equilibrium. However, when $k<0$, specifying parameters on production and utility functions and initial endowments randomly, this paper showed that the Lindahl tax is more desirable than the income tax (and proportional commodity tax) from the fairness and efficiency viewpoints with high possibility of existence for poll tax although the comparison between the poll tax and other taxes are impossible from the two viewpoints. Thus, this paper showed that the comparison completely depends on the substitution parameter of the CES utility function.

\section{ACKNOWLEDGMENT}

The present author appreciates the financial support provided by the JSPS KAKEN Grant Number 25380235.

\section{REFERENCES}

Fukiharu, T. [2012a]. "Public Good Provision: Lindahl Tax, Income Tax, Commodity Tax, and Poll Tax, A Simulation I.” (http://www.cc.aoyama.ac.jp/ fukito/IndexII.htm)

Fukiharu, T. [2012b]. "Public Good Provision: Lindahl Tax, Income Tax, Commodity Tax, and Poll Tax, A Simulation II.” (http://www.cc.aoyama.ac.jp/ fukito/IndexII.htm)

Fukiharu, T. [2013]. "Public Good Provision: Lindahl Tax, Income Tax, Commodity Tax, and Poll Tax, A Simulation III." (http://www.cc.aoyama.ac.jp/ fukito/IndexII.htm)

Layard, P.R.G. and A.A. Walters [1978], Microeconomic Theory, McGraw-Hill Book, U.K.

Shoven, J. B. and J. Whalley [1992], Applying General Equilibrium: Cambridge University Press

Stiglitz, J. E. [2000], Economics of the Public Sector, Third Edition, W.W. Norton \& Company. 